Tropical Journal of Pharmaceutical Research February 2017; 16 (2): 413-420

ISSN: $1596-5996$ (print); 1596-9827 (electronic) (c) Pharmacotherapy Group, Faculty of Pharmacy, University of Benin, Benin City, 300001 Nigeria.

\title{
Development and validation of a spectroscopic method for the simultaneous analysis of miconazole nitrate and hydrocortisone acetate in pharmaceutical dosage form
}

\author{
Nasir Abbas ${ }^{1}$, Muhammad Sohail Arshad ${ }^{2 \star}$, Amjad Hussain ${ }^{1}$, Muhammad Irfan $^{3}$, \\ Muhammad Ahsan ${ }^{1}$, Muhammad Fawad Rasool ${ }^{2}$ and Muhammad Hafeez ur \\ Rehman $^{4}$ \\ ${ }^{1}$ University College of Pharmacy, University of the Punjab, Lahore, ${ }^{2}$ Faculty of Pharmacy, Bahauddin Zakriya University, \\ Multan, ${ }^{3}$ Faculty of Pharmaceutical Sciences, Government College University, Faisalabad, ${ }^{4}$ Faculty of Pharmacy, Riphah \\ International University, Islamabad, Pakistan
}

*For correspondence: Email: Sohail_arshad79@yahoo.com; Fax: +92 61 9210089; Tel: +92 3334363634

Received: 19 August 2016

Revised accepted: 6 January 2017

\begin{abstract}
Purpose: To develop a new analytical method for the quantitative analysis of miconazole nitrate (MCN) and hydrocortisone (HCA) in pharmaceutical creams.

Methods: The study was accomplished in three steps. In the first stage, a spectroscopic method was developed for the simultaneous analysis of miconazole (MCN) and hydrocortisone (HCA). For this purpose, serial dilutions of both drugs were prepared using ethanol: water (50:50) as the solvent system. All solutions were analyzed for absorbance spectrophotometrically at 205 and $249 \mathrm{~nm}$ for MCN and $H C A$, respectively. The method was validated for linearity, range, accuracy, precision and robustness. A commercial formulation was also assayed by the proposed method.

Results: The absorbance data were linear over a concentration range of 1 to $12 \mu \mathrm{g} / \mathrm{mL}$ for MCN and 1 to $40 \mu \mathrm{g} / \mathrm{mL}$ for $\mathrm{HCA}$, with correlation coefficient of 0.9995 and 0.9984 , respectively. Limit of detection (LOD) and of quantification (LOQ) of $M C N$ were 0.49 and $1.49 \mu \mathrm{g} / \mathrm{mL}$, respectively, and for HCA, 1.50 and $4.57 \mu \mathrm{g} / \mathrm{mL}$, respectively. The assay results for the commercial formulation were within the limits specified in British Pharmacopoeia.

Conclusion: Simultaneous quantification of miconazole (MCN) and hydrocortisone (HCA) by UV spectroscopy provides a simple, reliable and robust method for the characterization of a mixture of the drugs in a dosage form.
\end{abstract}

Keywords: Simultaneous analysis, Miconazole nitrate, Hdrocortisone acetate, UV-visible spectroscopy, Method validation

Tropical Journal of Pharmaceutical Research is indexed by Science Citation Index (SciSearch), Scopus, International Pharmaceutical Abstract, Chemical Abstracts, Embase, Index Copernicus, EBSCO, African Index Medicus, JournalSeek, Journal Citation Reports/Science Edition, Directory of Open Access Journals (DOAJ), African Journal Online, Bioline International, Open-J-Gate and Pharmacy Abstracts

\section{INTRODUCTION}

Synergistic combinations of different drugs are frequently prescribed for the treatment of complex pathologic conditions [1]. Formulations are also designed for such combinations as they improve patient compliance and to reduce cost of treatments. Complexity in the formulation requires modification of the analytical method. There are numerous literature evidences to demonstrate the analysis of drugs from combination dosage forms. These emphasize either separation of individual components or simultaneous analysis by using different advanced analytical methods such as high pressure liquid chromatography (HPLC) [2-4] 
Gas chromatography [5-7] HPTLC [8,9], fluoromertric method [10], micellar electrokinetic chromatographic method [11], bioanalytical method [12], photochemical reaction [13] and voltametric methods [14]. Although these techniques are reported with improved sensitivity for the measurement of the minute quantities of medicines in a dosage forms, these techniques are expansive to install and requires a higher degree of operator skill.

Pharmaceutical analysts frequently desire simpler methods for the quantification of medicines from dosage forms containing two or more substances [15]. As a bench marks of batch reproducibility, it is desirable to perform a faster analysis of the active pharmaceutical ingredients at in process stage or after final formulation. One such approach is development of analytical method for the quantification of combination dosage form using UV-visible spectrophotometer. Since this tool is well established, economical and simple, extension of its application will be of great benefit to analysts [16].

Miconazole nitrate is an antifungal agent which belongs to chemical class of imidazoles, having molecular formula $\mathrm{C}_{18} \mathrm{H}_{14} \mathrm{Cl}_{4} \mathrm{~N}_{2} \mathrm{O}$ [17]. It shows invitro activity against dermatophytes (e.g., Epidermophyton floccosum, Trichophyton mentagrophytes), some actinomycetes (e.g., Streptomyces madurae, Nocardia asteroides), and yeasts (e.g., Candida albicans, Pityrosporum orbiculare and pachydermatis, Cryptococcus neoformans). It also shows activity against some anaerobic and Gram positive bacteria (e.g., Staphylococcus aureus, Streptococcus faecalis, Bacteroides fragilis) [18]. Oral gel and tablets of miconazole are used to treat oral candidiasis.

Hydrocortisone acetate also known as (11 $\beta$ )pregn-4-ene-3, 20-dione,11, 17, 21-trihydroxy with a chemical formula of $\mathrm{C}_{21} \mathrm{H}_{30} \mathrm{O}_{5}$, is a naturally occurring glucocorticoid hormone, which has many physiological effects i.e. intermediary metabolism regulation, cardiovascular function, immunity and growth. It is bound to corticosteroid binding globulin (CBG) which is an alpha-2 globulin produced by liver. 90 $\%$ of hydrocortisone is bound to it during normal conditions. 5 - $10 \%$ of hydrocortisone is free or bound to albumin to exert its action on target cells [17]. Miconazole nitrate $2 \% \mathrm{w} / \mathrm{w}$ and hydrocortisone acetate $1 \% \mathrm{w} / \mathrm{w}$ are used in combination topically to treat various skin infections e.g. athlete's foot and candidal intertrigo [19].
Despite the fact that these two medicines (MCN and HCA) are co-formulated as topical preparation, no ultraviolet-visible spectroscopybased analytical method was found in the literature. The aim of this study was to develop an ultraviolet spectroscopy based method for the simultaneous determination of $\mathrm{MCN}$ and $\mathrm{HCN}$ in a pharmaceutical dosage form.

\section{EXPERIMENTAL}

\section{Materials}

Miconazole nitrate (MCN) and hydrocortsione $(\mathrm{HCN})$ were received as a gift from Fassgen Pharmaceuticals Private Limited, Islamabad, Pakistan. All the other chemicals used including ethanol, methanol, hydrochloric acid and sodium hydroxide were of analytical grade. Two marketed creams containing MCN and HCA were purchased from a local pharmacy in Islamabad, Pakistan.

\section{Preparation of standard solutions}

Standard solutions of each drug were prepared in three different solvents namely $0.1 \mathrm{~N} \mathrm{HCl}, 0.1$ $\mathrm{N} \mathrm{NaOH}$ and $50 \%$ ethanol. For this purpose, 1 $\% \mathrm{w} / \mathrm{v}$ stock solutions of $\mathrm{MCN}$ and HCA was prepared by dissolving $1 \mathrm{~g}$ of each drug in the given solvent ( $100 \mathrm{~mL}$ q.s). These solutions were sonicated for 5 minutes to ensure a complete dissolution of the drug substances and labeled as stock solutions. A further dilution of the stock solutions (to $0.01 \% \mathrm{v} / \mathrm{v}$, i.e., $1: 100$ ) was made to obtain a working standard of $100 \mu \mathrm{g} / \mathrm{mL}$ concentration of the drug.

\section{Determination of lambda maximum ( $\lambda$ max)}

For the determination $\lambda_{\max }$ of both drugs, ethanoic solutions containing $10 \mu \mathrm{g} / \mathrm{mL}$ of each drug were scanned over a wavelength range of $200 \mathrm{~nm}$ to $400 \mathrm{~nm}$ using Jasco UV-Visible spectrophotometer (Double beam, Model: Jasco $\mathrm{V}-530$, equipped with quartz cuvettes of path length $1 \mathrm{~cm}$ ) by using $50 \%$ ethanol as blank. The overlay spectra of both drugs are shown in Figure 1.

The wavelengths showing maximum absorbance $\left(\lambda_{\max }\right)$ at 205 and $249 \mathrm{~nm}$ for MCN and HCA, respectively were used for the development and validation of method for simultaneous quantification of subject drugs. 


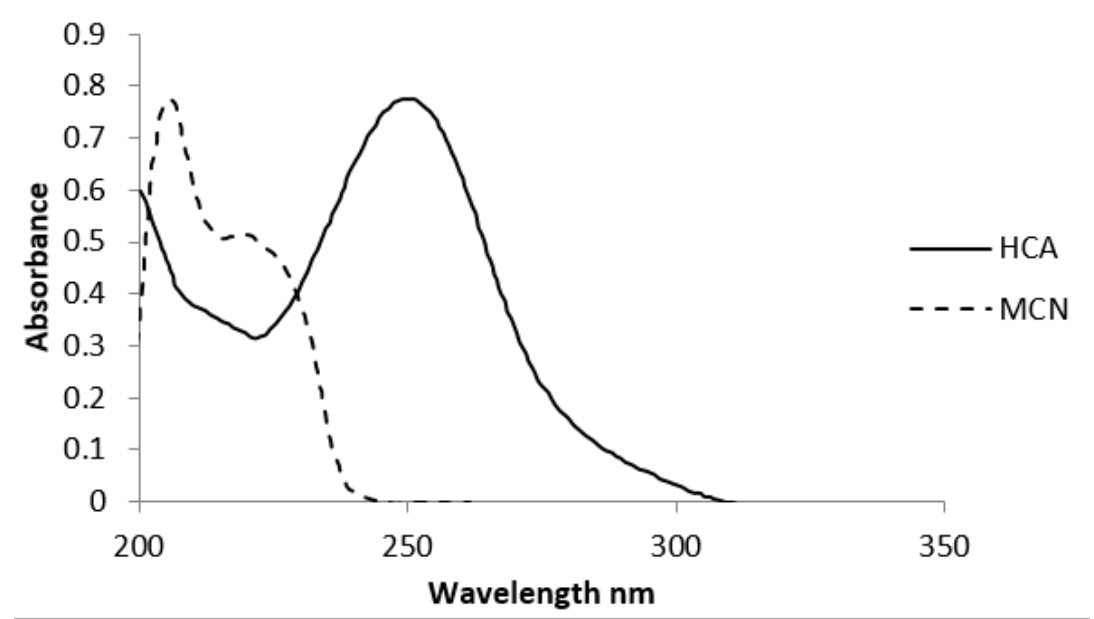

Figure 1: UV-Visible spectra of MCN and HCA

\section{Determination of linear range}

Linearity of the method was determined by using four different series of solutions of both drugs named as series 1 to 4 . Series 1 and 2 includes separate solutions of MCN and HCA ranging from 1 to $12 \mu \mathrm{g} / \mathrm{mL}$ and 1 to $40 \mu \mathrm{g} / \mathrm{mL}$, respectively. While series 3 and 4 were binary solutions containing combination of drugs in different ranges i.e. in series 3 the concentration of HCA was kept constant $(10 \mu \mathrm{g} / \mathrm{mL})$ while the concentration of MCN was increased from 1 to $12 \mu \mathrm{g} / \mathrm{mL}$. In the series 4 , the concentration of MCN was kept constant $(10 \mu \mathrm{g} / \mathrm{mL})$ while the concentration of HCA was increased from 1 to 40 $\mu \mathrm{g} / \mathrm{mL}$. All the above prepared dilutions were analyzed at the maximum wavelengths $\left(\lambda_{\max }\right)$ for each drug as described above. In all the cases, ethanol $(50 \% \mathrm{w} / \mathrm{v})$ was used as blank.

\section{Determination of LOD, LOQ, Precision, accuracy and robustness of the analytical method}

Limit of detection (LOD) and limit of quantification (LOQ) of the both drugs were determined by the formula as shown in Eq 1 and 2, respectively. LOD refers to the lowest concentration of drug which can be detected reliably. At this concentration the signals are well differentiated from the noise levels (signal to noise ration 3:1). LOQ is the lowest amount of drug that can be measured with appropriate precision and accuracy. At LOQ the signal to noise ratio is 10:1.

$L O D=3 \times \frac{S D}{b}$
$L O Q=10 \times \frac{S D}{b}$

where SD is standard deviation at low concentration and $b$ is slope of calibration. The accuracy of this method was ascertained by determining the percentage recovery of drug(s) from all the standard solutions with known drug concentrations. The precision was determined in terms of intra-day precision (repeatability), interday precision (intermediate precision) and precision between laboratories (reproducibility). The study was performed at three concentration levels and for each concentration, five replicate were used for the test.

Robustness, ability of the method to remain unaffected by small change in the method, was determined by recording absorbance of a sample at slightly different temperature and $\mathrm{pH}$.

Application of validated method to physical drug mixture and commercial cream

In the second stage of study the validated method was tested on the physical mixture of both drug and on a commercial topical cream. Physical mixture containing 20 and $10 \mathrm{mg}$ of MCN and HCA, respectively was prepared and analyzed by using at $\lambda_{\max }$ of respective drugs. The average absorbance data from five observations were used for the precise determination of drug contents in the solution.

Commercial topical cream containing 2 and $1 \%$ $\mathrm{w} / \mathrm{w}$ of MCN and HCA was used to test the developed method. For this, purpose $1.0 \mathrm{~g}$ of the cream was dissolved in $100 \mathrm{ml}$ ethanol $50 \%$. The solution was filtered through Whatman filter paper after sonication of $5 \mathrm{~min}$. The filtrate was further diluted (to 1:20) using the same solvent to make a second dilution containing $\mathrm{MCN}$ and of $\mathrm{HCA}$ at concentration of 10 and $5 \mu \mathrm{g} / \mathrm{mL}$, respectively. The absorbance $(A)$ of both the samples was measured at the $\lambda_{\max }$ of both the drugs using $50 \%$ ethanol as blank solution. The percent contents of each drug were calculated using Eqs 3 and 4. 
$\operatorname{MCN}(\%)=(\mathrm{At} / \mathrm{As}) 100$

where At and As are the absorbance of test and standard samples, respectively at $205 \mathrm{~nm}$.

$\operatorname{HCA}(\%)=(\mathrm{At} / \mathrm{As}) 100$

where At and As are the absorbance of test and standard samples, respectively at $249 \mathrm{~nm}$.

Data analysis was carried out for the determination of accuracy, linearity, precision, mean, standard deviation, relative standard deviation, percent recovery and robustness by using Microsoft Excel.

\section{RESULTS}

\section{Linearity}

The calibration curves obtained from the four sets of solutions (namely 1 to 4) are shown in Figure 2. The absorbance data of MCN, recorded at $205 \mathrm{~nm}$, with increasing concentrations (up to $12 \mu \mathrm{g} / \mathrm{ml}$ ) showed a linear correlation $R^{2}=0.999$ for both types of solutions containing $\mathrm{MCN}$ alone and in combination with HCA. Similarly, the absorbance data of HCA, recorded at $249 \mathrm{~nm}$, with increasing concentrations (up to $40 \mu \mathrm{g} / \mathrm{ml}$ ) showed a linear correlation $\mathrm{R}^{2}=0.9998$ for both types of solutions containing HCA alone and in combination with MCN. This trend confirms that the absorbance
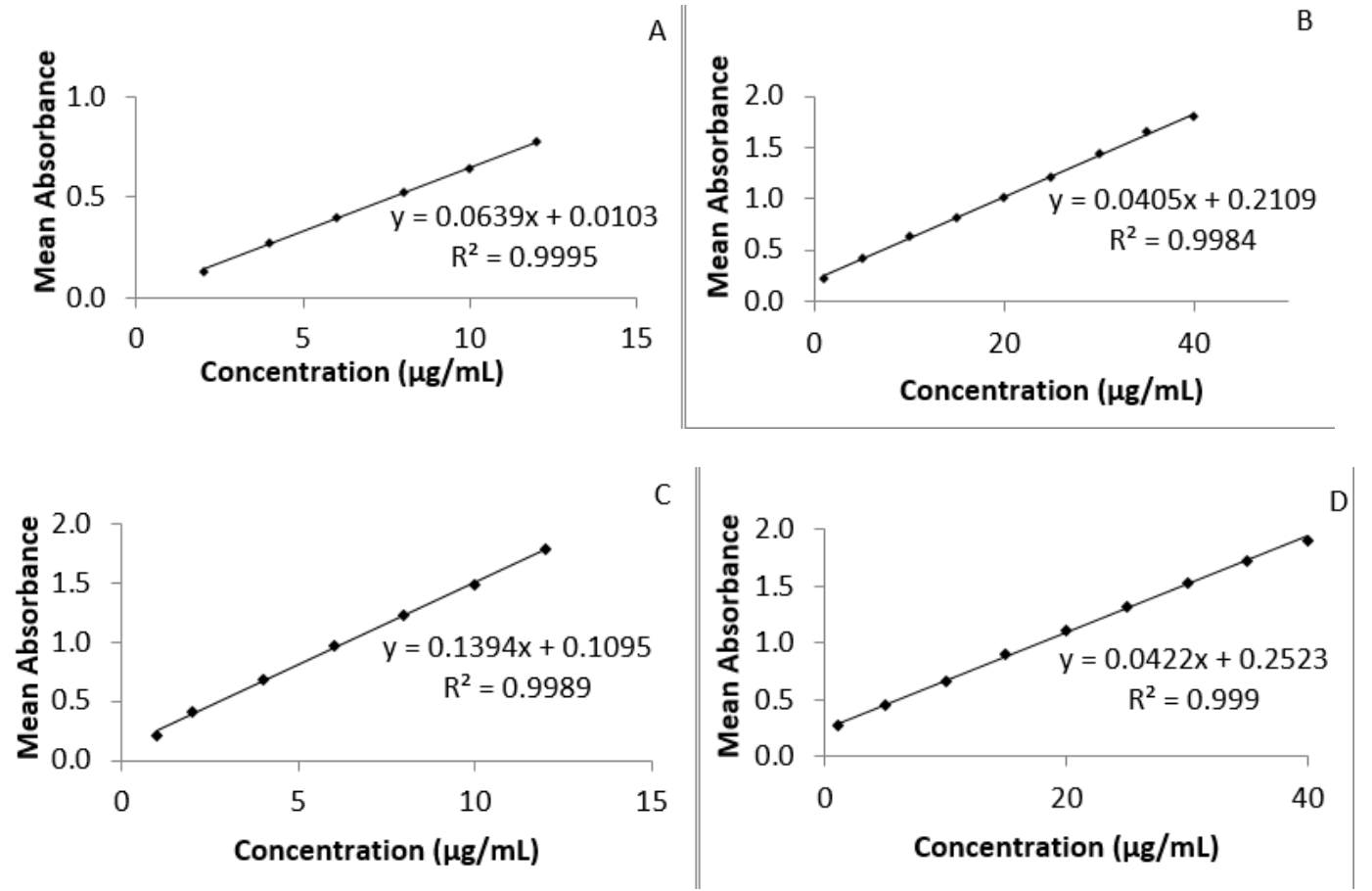

Figure 2: Calibration curves of $(A) M C N,(B) H C A,(C) M C N$ in the presence of HCA and (D) HCA in the presence of MCN profiles for both drugs (either alone or in combination) follow the Beer Lambert law [20], suggesting that the absorbance is proportional to the concentration of the respective analytes.

The extinction coefficient's value from this study was in good agreement with the one described in literature which in essence proves the validity of the method.

Other parameters of equations describing the linear function i.e. slope and intercept showed an increase in their values from 0.0639 to 0.1394 and 0.0103 to 0.1095 , respectively for MCN. The absorbance data of hydrocortisone in binary solution, on the other hand, have shown no change in the values of slope and differ from the test solution in terms of its intercept value; the former being elevated to 0.2523 from 0.2190 .

\section{Limit of detection and of quantification}

Limit of detection (LOD) and of quantification (LOQ), were determined as a part of validation protocol on the prescribed analytical method. For binary solutions of MCN and HCA (latter at fixed concentration), LOD and $L O Q$ values for MCN were calculated as $0.4944 \mu \mathrm{g} / \mathrm{mL}$ and 1.4938 $\mu \mathrm{g} / \mathrm{mL}$, respectively. Similarly, LOD and LOQ for binary solutions containing $\mathrm{HCA}$ and MCN (latter at fixed concentrations) for HCA were found to be 1.5081 and $4.5702 \mu \mathrm{g} / \mathrm{mL}$, respectively.

B

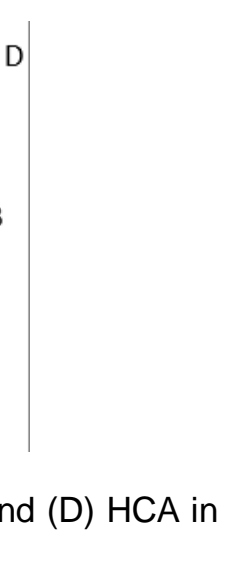




\section{Accuracy}

The accuracy studies were performed by determining the percentage recovery of drug(s) from all the solutions containing individual drug substance as well as from binary solutions. The percentage recovery for all the solutions were found to be in the range of $99-102 \%$. The results for these studies are summarizes in Table 1 and Table 2.

\section{Precision}

The precision of this analytical procedure was determined in terms of intra-day precision (repeatability), inter-day precision (intermediate precision) and precision between laboratories (reproducibility). These studies were performed at three levels of drug concentrations (i.e., 6, 8, $10 \mu \mathrm{g} / \mathrm{mL}$ and $5,10,15 \mu \mathrm{g} / \mathrm{mL}$ for $\mathrm{MCN}$ and $\mathrm{HCA}$, respectively) and for each concentration the absorbance was recorded as five replicates. The results are described in terms of concentration $(\mu \mathrm{g} / \mathrm{mL})$ and in \% RSD (Table 3).

\section{Robustness}

The robustness of the method was established from the changes in $\lambda_{\max }$ in response to slight changes in temperature and $\mathrm{pH}$. The $\lambda_{\max }$ for both drug was largely unaffected by changes in temperature $25 \pm 3^{\circ} \mathrm{C}$. Figure $3 \mathrm{~A}$ and $\mathrm{B}$ shows changes in the position of $\lambda_{\max }$ of MCN and HCA, respectively. The $\lambda_{\max }$ of HCA was persistent in both acidic $(0.1 \mathrm{~N} \mathrm{HCl})$ and alkaline $(0.1 \mathrm{~N}$ $\mathrm{NaOH}$ ) conditions. In the case of $\mathrm{MCN}, \lambda_{\max }$ was least affected in acidic $\mathrm{pH}$, however, bathochromic shift was observed at higher $\mathrm{pH}$ conditions (i.e., $0.1 \mathrm{~N} \mathrm{NaOH}$ ). The above results suggest that this approach is fairly robust in terms of thermal changes and decrease in $\mathrm{pH}$.

Table 1: Recovery and accuracy of $\mathrm{MCN}$ alone and in binary (MCN $+\mathrm{HCA}$, the latter in fixed concentration) solutions at concentrations ranging from 4 to $12 \mu \mathrm{g} / \mathrm{mL}$

\begin{tabular}{lcccccc}
\hline $\begin{array}{l}\text { Concentration } \\
(\boldsymbol{\mu g} / \mathbf{m L})\end{array}$ & $\begin{array}{c}\text { Mean } \\
\text { absorbance } \\
(\mathbf{n}=5)\end{array}$ & $\begin{array}{c}\text { MCN } \\
\text { Concentration } \\
\text { recovered } \\
(\mu \mathbf{g} / \mathbf{m L})\end{array}$ & $\begin{array}{c}\text { Mean \% } \\
\text { accuracy }\end{array}$ & $\begin{array}{c}\text { Mean absorbance } \\
(\mathbf{n}=5)\end{array}$ & $\begin{array}{c}\text { Concentration } \\
\text { recovered } \\
(\boldsymbol{\mu g} / \mathbf{m L})\end{array}$ & $\begin{array}{c}\text { Mean \% } \\
\text { accuracy }\end{array}$ \\
\hline 12 & $0.7788 \pm 0.010$ & $12.03 \pm 0.03$ & $100.22 \pm 1.02$ & $1.7802 \pm 0.012$ & $11.9849 \pm 0.13$ & $99.87 \pm 1.03$ \\
10 & $0.6419 \pm 0.008$ & $9.88 \pm 0.12$ & $98.84 \pm 0.99$ & $1.4898 \pm 0.0078$ & $9.9017 \pm 0.27$ & $99.01 \pm 1.4$ \\
8 & $0.523 \pm 0.01$ & $8.02 \pm 0.05$ & $100.29 \pm 1.05$ & $1.2256 \pm 0.010$ & $8.0064 \pm 0.19$ & $100.08 \pm 1.08$ \\
6 & $0.3955 \pm 0.007$ & $6.03 \pm 0.15$ & $100.46 \pm 1.11$ & $0.9673 \pm 0.0071$ & $6.1535 \pm 0.08$ & $102.55 \pm 2.01$ \\
4 & $0.2722 \pm 0.001$ & $4.10 \pm 0.05$ & $102.46 \pm 1.81$ & $0.6768 \pm 0.0057$ & $4.0695 \pm 0.11$ & $101.73 \pm 2.05$ \\
\hline
\end{tabular}

Table 2: Recovery and accuracy results of $\mathrm{HCA}$ alone or in binary $(\mathrm{HCA}+\mathrm{MCN}$, the latter in fixed concentration) at concentrations ranging from 15 to $35 \mu \mathrm{g} / \mathrm{mL}$

\begin{tabular}{lcccccc}
\hline $\begin{array}{l}\text { Conc. } \\
(\boldsymbol{\mu g} / \mathbf{m L})\end{array}$ & $\begin{array}{c}\text { Mean } \\
\text { absorbance } \\
(\mathbf{n}=5)\end{array}$ & $\begin{array}{c}\text { Concentration } \\
\text { recovered } \\
(\boldsymbol{\mu g} / \mathbf{m L})\end{array}$ & $\begin{array}{c}\text { Mean } \\
\text { accuracy }(\%)\end{array}$ & $\begin{array}{c}\text { Mean } \\
\text { absorbance } \\
(\mathbf{n}=5)\end{array}$ & $\begin{array}{c}\text { HCA in the presence of MCN } \\
\text { Concentration } \\
\text { recovered } \\
(\boldsymbol{\mu} \mathbf{g} / \mathbf{m L})\end{array}$ & Mean \\
\hline 15 & $0.8108 \pm 0.013$ & $14.80 \pm 0.23$ & $98.74 \pm 1.3$ & $0.6661 \pm 0.014$ & $9.8056 \pm 0.02$ & $98.05 \pm 0.97$ \\
20 & $1.0118 \pm 0.01$ & $19.78 \pm 0.05$ & $98.87 \pm 0.99$ & $1.1119 \pm 0.17$ & $20.3696 \pm 0.016$ & $101.84 \pm 1.15$ \\
25 & $1.2156 \pm 0.03$ & $24.81 \pm 0.04$ & $99.22 \pm 1.43$ & $1.3184 \pm 0.084$ & $25.2630 \pm 0.024$ & $101.05 \pm 1.21$ \\
30 & $1.4465 \pm 0.012$ & $30.51 \pm 0.12$ & $101.69 \pm 1.6$ & $1.5303 \pm 0.055$ & $30.2843 \pm 0.03$ & $100.94 \pm 1.47$ \\
35 & $1.6503 \pm 0.01$ & $35.54 \pm 0.03$ & $101.54 \pm 1.49$ & $1.7295 \pm 0.12$ & $35.0047 \pm 0.19$ & $100 . \pm 0.9701$ \\
\hline
\end{tabular}

Table 3: Precision of analytical methods for assay of MCN and HCA

\begin{tabular}{|c|c|c|c|c|c|c|c|}
\hline \multirow[t]{2}{*}{ Drug } & \multirow[b]{2}{*}{$\begin{array}{l}\text { Conc. } \\
(\mu \mathrm{g} / \mathrm{mL})\end{array}$} & \multicolumn{2}{|c|}{ Intra-day precision $(n=5)$} & \multicolumn{2}{|c|}{ Inter-day precision $(n=5)$} & \multicolumn{2}{|c|}{$\begin{array}{c}\text { Inter-lab precision } \\
(\mathrm{n}=5)\end{array}$} \\
\hline & & $\begin{array}{l}\text { Concentratio } \\
n(\mu g / m L) \\
\pm S D\end{array}$ & RSD (\%) & $\begin{array}{c}\text { Concentration } \\
(\mu g / m L) \\
\pm S D\end{array}$ & $R S D(\%)$ & $\begin{array}{c}\text { Concentration } \\
\begin{array}{c}(\mu \mathrm{g} / \mathrm{mL}) \\
\pm S D\end{array}\end{array}$ & $\begin{array}{l}R S D \\
(\%)\end{array}$ \\
\hline \multirow[t]{3}{*}{ MCN } & 6 & $6.11 \pm 0.08$ & 1.43 & $6.01 \pm 0.10$ & 1.75 & $5.94 \pm 0.03$ & 0.65 \\
\hline & 8 & $7.98 \pm 0.08$ & 1.06 & $7.98 \pm 0.06$ & 0.75 & $7.93 \pm 0.08$ & 1.06 \\
\hline & 10 & $10.62 \pm 0.12$ & 1.20 & $10.67 \pm 0.11$ & 1.10 & $10.54 \pm 0.08$ & 0.84 \\
\hline \multirow[t]{3}{*}{$\mathrm{HCA}$} & 5 & $5.10 \pm 0.08$ & 1.70 & $4.98 \pm 0.03$ & 0.79 & $5.07 \pm 0.06$ & 1.23 \\
\hline & 15 & $14.99 \pm 0.14$ & 0.96 & $15.36 \pm 0.21$ & 1.40 & $15.45 \pm 0.27$ & 1.79 \\
\hline & 25 & $25.41 \pm 0.31$ & 1.25 & $24.93 \pm 0.18$ & 0.73 & $26.11 \pm 0.51$ & 1.97 \\
\hline
\end{tabular}



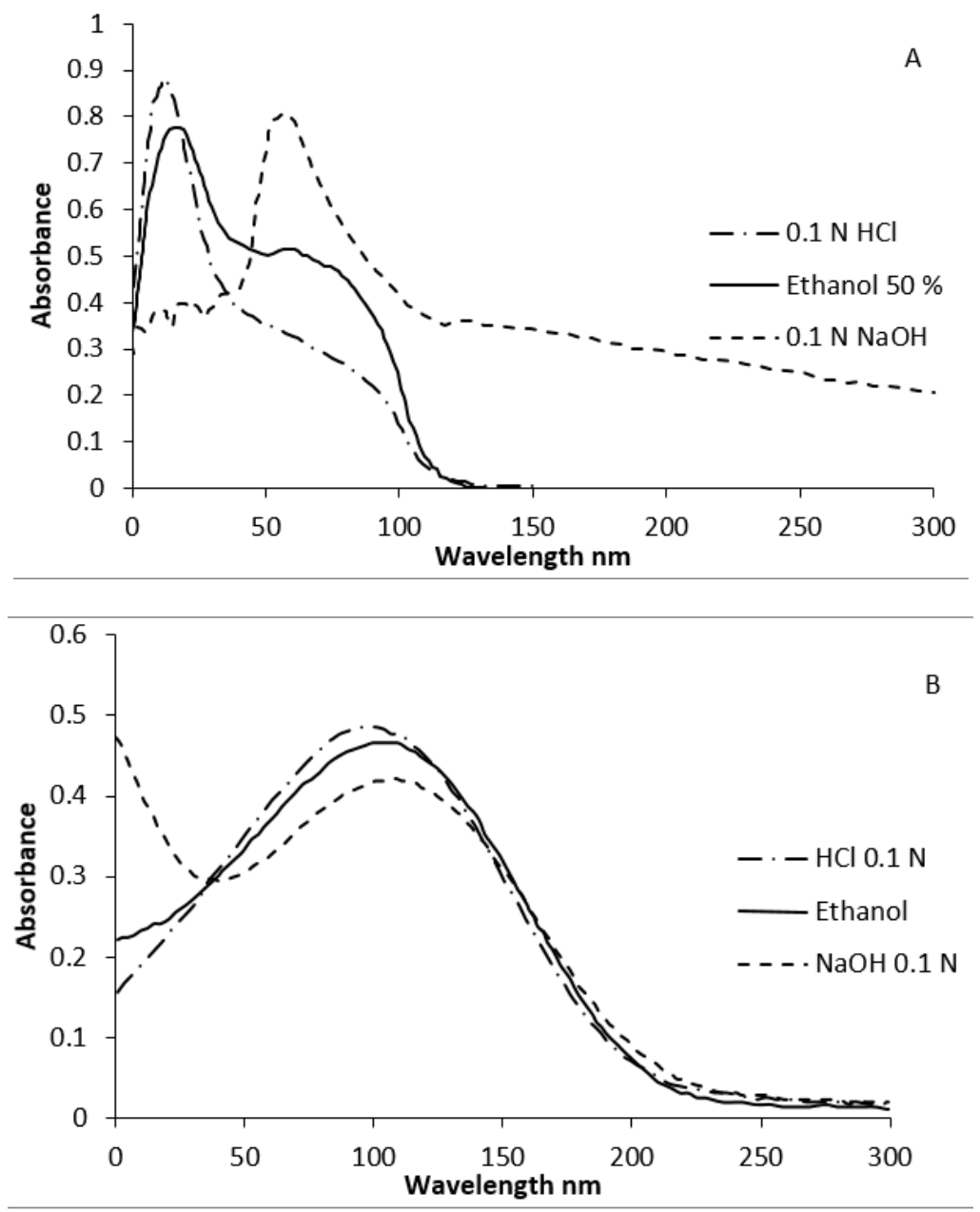

Figure 3: UV-visible spectra in the range of $200-300 \mathrm{~nm}$, A) MCN and B) HCA following the addition of acid and alkali indicating robustness of the analytical method

Table 3: Assay results of physical mixture and commercial brand of MCN and HCA using UV-visible spectroscopy and HPLC

\begin{tabular}{lllll}
\hline Type & Drug & $\begin{array}{l}\text { Mean UV } \\
\text { absorbance of } \\
\text { sample }(\mathbf{n}=5)\end{array}$ & $\begin{array}{l}\text { Label } \\
\text { strength }(\%) \\
(\%)-\text { UV } \\
\text { method }\end{array}$ & $\begin{array}{l}\text { Label } \\
\text { strength (\%) } \\
(\%)-\text { HPLC } \\
\text { method }\end{array}$ \\
\hline Commercial & Miconazole & $0.8055 \pm 0.02$ & $102.26 \pm 1.76$ & $101.39 \pm 1.01$ \\
cream & Hydrocortisone & $0.2300 \pm 0.011$ & $99.64 \pm 0.98$ & $100.43 \pm 0.97$ \\
Physical & Miconazole & $0.7877 \pm 0.027$ & $100.26 \pm 1.04$ & $101.39 \pm 0.99$ \\
Mixture & Hydrocortisone & $0.2308 \pm 0.009$ & $100.64 \pm 1.1$ & $100.43 \pm 1.05$ \\
\hline
\end{tabular}

Assay results for commercial cream available HPLC method specified in British product Pharmacopoeia (2008).

The validity of the developed method was assessed by performing the assay on the physical mixture $(20$ and $10 \mathrm{mg} \mathrm{MCN}$ and HCA, respectively) and on commercially available cream (labeled claim 2 and $1 \% \mathrm{MCN}$ and HCA, respectively). The results are shown in table 4 . The results obtained by UV spectroscopic analysis were further compared with the already

\section{DISCUSSION}

Various researchers have proposed different methods for the determination of miconazole nitrate (MCN) and hydrocortisone acetate (HCNA) separately or in combination with some other drugs [21] in various dosage forms using varieties of analytical techniques. However, literature survey has shown that no analytical 
method based on the simultaneous analysis of MCN and HCA by UV spectroscopic method has been reported previously. In comparison to other techniques, UV analyses are often preferred in quality control testing in a pharmaceutical industry where faster, robust and easily performing methods are required at the in process and finished stage of pharmaceutical dosage form. The objective of this study was to develop and validate a simpler and reliable UVspectrophotometric method for the simultaneous determination of MCN and HCA in pharmaceutical dosage form. The proposed method in this study has exhibited precise, accurate and robust assay for concomitant determination of MCN and HCA in physical mixture as well as in formulated creams. Furthermore the results have also shown that the proposed method is comparable with already available HPLC method in respect of sensitivity and recovery of active pharmaceutical ingredient. The wavelengths showing maximum absorbance $\left(\lambda_{\max }\right)$ i.e. 205 and $249 \mathrm{~nm}$ for $\mathrm{MCN}$ and HCA, respectively were well resolved and showed no interference this shows the developed method is selective for both drugs. The calibration curves were found linear for the single and binary solution of MCN and HCA in the range 1 to 12 $\mu \mathrm{g} / \mathrm{mL}$ and 1 to $40 \mu \mathrm{g} / \mathrm{mL}$, respectively. In case of binary solutions, other parameters of line equations describing the linear function i.e. slope and intercept showed an increase in their values from 0.0639 to 0.1394 and 0.0103 to 0.1095 , respectively for MCN. One may argue that such increments in the absorbance are the consequence of contribution from the $\mathrm{HCN}$; the linear behavior recorded from the absorbance data might be satisfactory to estimate the concentration of MCN. The absorbance data of hydrocortisone in binary solution, on the other hand, differ slightly from the test solution only in terms of its intercept value; the former being elevated from 0.219 to 0.2523 . In response to the sensitivity of the developed method the results of LOD and LOQ shows that the proposed method is sensitive for both drugs and can easily quantify minimum concentration of $1.49 \mu \mathrm{g} / \mathrm{mL}$ for $\mathrm{MCN}$ and $4.57 \mu \mathrm{g} / \mathrm{mL}$ for $\mathrm{HCA}$. The percentage recovery (accuracy) results for both drugs were in the range of 99 to $102 \%$ showing a comparative accuracy as compare to HPLC method. The precision of proposed analytical procedure was determined in terms of intra-day precision (repeatability), inter-day precision (intermediate precision) and precision between laboratories (reproducibility). These studies were performed at three levels of drug concentrations (i.e. $6,8,10 \mu \mathrm{g} / \mathrm{mL}$ and $5,10,15 \mu \mathrm{g} / \mathrm{mL}$ for $\mathrm{MCN}$ and HCA, respectively). The RSD values obtained from all of these experiments were found within the range with maximum RSD value of $1.97 \%$.

Robustness of the method can be described by the response of develop method with slight changes in temperature and $\mathrm{pH}$. Our results has shown that he prescribed method is robust for analysis of both drugs in response to thermal changes and slight decrease in $\mathrm{pH}$. However, in case of $\mathrm{MCN}$, bathochromic shift was observed at higher $\mathrm{pH}$ conditions (i.e. $0.1 \mathrm{~N} \mathrm{NaOH}$ ). This might be due to the ionization of $\mathrm{MCN}$ at higher $\mathrm{pH}$. Therefore one should ensure a minimum increase in the $\mathrm{pH}$ while using this method.

The developed simultaneous method was also assessed for its validity by performing assay on physical mixture of the drugs as well as on commercially available cream. The results show that the method was successfully employed on these samples. Furthermore, these results are also comparable with the HPLC method.

\section{CONCLUSION}

Based on the requirements of International Conference of Harmonization (ICH), the developed method is accurate, precise, robust, reliable and an alternate method for the simultaneous analysis of miconaole (MCN) and hydrocortisone (HCA) in pharmaceutical dosage forms. Furthermore, there is no need for any special pre-treatment of the sample for analysis. Compared to a previously reported HPLC method for the simultaneous quantification of these drugs, the present method is cost-effective, less time-consuming, and no special expertise is required for analysis of the drugs and handling of equipment.

\section{DECLARATIONS}

\section{Acknowledgement}

The authors express their gratitude to Fassgen Pharmaceuticals Private Limited, Islamabad, Pakistan for the gift of pure drug samples.

\section{Conflict of Interest}

No conflict of interest associated with this work.

\section{Contribution of Authors}

The authors declare that this work was done by the authors named in this article and all liabilities pertaining to claims relating to the content of this article will be borne by them. 


\section{Open Access}

This is an Open Access article that uses a funding model which does not charge readers or their institutions for access and distributed under the terms of the Creative Commons Attribution License (http://creativecommons.org/licenses/by 14.0) and the Budapest Open Access Initiative (http://www.budapestopenaccessinitiative.org/rea d), which permit unrestricted use, distribution, and reproduction in any medium, provided the original work is properly credited.

\section{REFERENCES}

1. Lehar J, Krueger AS, Avery W, Heilbut AM, Johansen $L M$, Price ER, Rickles RJ, Short lii GF, Staunton JE, Jin $X$ et al.. Synergistic drug combinations improve therapeutic selectivity. Nat Biotechnol 2009; 27(7): 659666. doi: $10.1038 /$ nbt. 1549.

2. Petersen MC, Nation RL, Ashley JJ. Simultaneous determination of betamethasone, betamethasone acetate and hydrocortisone in biological fluids using high-performance liquid chromatography. J Chromatogr B Biomed Sci Appl 1980; 183(2): 131-139.

3. Lea A, Kennedy J, Low G-C. Analysis of hydrocortisone acetate ointments and creams by high-performance liquid chromatography. J Chromatogr A 1980; 198(1): 41-47.

4. Birsan M, Cojocaru IC, Scutariu MM, Popovici I. Validation of a chromatographic method for miconazole assay from oral sustained release mucoadhesive tablets. Farmacia 2014; 62: 555-563.

5. Wallace S, Shah V, Riegelman S, Epstein W. Electron capture Gas Chromatographic assay for Miconazole and Clotrimazole in skin samples. Anal Lett1978; 11(6): 461468.

6. Ekiert R, Krzek J, Czekaj J, Hubicka U. Evaluation of a CGC-FID method for qualitative and quantitative analysis of azole antifungal drugs. Acta Chromatogr 2009; 21(2): 273-282.

7. Ashour S, Kattan N. Simultaneous determination of miconazole nitrate and metronidazole in different pharmaceutical dosage forms by gas chromatography and flame ionization detector (GC-FID). Int J Biomed Sci 2010; 6(1): 13-18.

8. Pagare PK, Satpute CS, Jadhav VM, Kadam V. Forced degradation studies and validated stability-indicating HPTLC method for determination of miconazole nitrate in soft lozenges. Lib Der Pharma Lettr 2012; 4(6): 17931804.

9. Salama I, Gomaa MS. Comparative determination of miconazole, nystatin, hydrocortisone and neomycin by HPTLC/HPLC-DAD. Eur J Chem 2013; 4(1): 29-34.

10. Silber RH, Busch RD, Oslapas R. Practical procedure for estimation of corticosterone or hydrocortisone. Clin Chem 1958; 4(4): 278-285.

11. Lemus Gallego J, Arroyo JP. Determination of hydrocortisone and associated compounds in pharmaceutical preparations by micellar electrokinetic chromatography. J Liq Chromatogr Relat Technol 2003; 26(7): 1011-1025.

12. Wu S, Li W, Mujamdar T, Smith T, Bryant M, Tse FL. Supported liquid extraction in combination with LC-MS/MS for high-throughput quantitative analysis of hydrocortisone in mouse serum. Biomed Chromatogr 2010; 24(6): 632-638.

13. Cardoso CE, Martins RO, Telles CA, Aucélio RQ. Sequential determination of hydrocortisone and epinephrine in pharmaceutical formulations via photochemically enhanced fluorescence. Mikrochim Acta 2004; 146(1): 79-84.

14. Balaji K, Reddy GR, Reddy TM, Reddy SJ. Determination of prednisolone, dexamethasone and hydrocortisone in pharmaceutical formulations and biological fluid samples by voltammetric techniques using $\beta$-cyclodextrin modified carbon paste electrode. Afr $J$ Pharm Pharmacol 2008; 2: 157-66.

15. Valliyodan B, Shi $H$, Nguyen HT. A Simple Analytical Method for High-Throughput Screening of Major Sugars from Soybean by Normal-Phase HPLC with Evaporative Light Scattering Detection. Chromatogr Res Int 2015; 2015: 8. doi:10.1155/2015/757649.

16. Gorog S. Ultraviolet-visible Spectrophotometry in Pharmaceutical Analysis: Application of UV-VIS Spectroscopy in Pharmaceutical. Florida: CRC; 1995.

17. Remington JP, Troy $D B$, Beringer $P$. Remington: The science and practice of pharmacy. Philadelphia: Lippincott Williams \& Wilkins; 2006.

18. Heel R, Brogden R, Pakes G, Speight $T$, Avery G. Miconazole: a preliminary review of its therapeutic efficacy in systemic fungal infections. Drugs. 1980; 19(1): 7-30.

19. Committee JF, Britain RPSoG. British national formulary. Pharmaceutical Press; 2012.

20. Calloway D. Beer-lambert law. J Chem Educ 1997; 74(7): 744.

21. British Pharmacopoeia. British Pharmacopoiea Commission. London: 2008 